\title{
Is Totally Laparoscopic Total Gastrectomy Better Than Laparoscopy- Assisted Total Gastrectomy For Clinical Stage I Gastric Cancer? A Propensity-Score Matched Analysis
}

\section{Shin-Hoo Park}

Seoul National University College of Medicine

Yun-Suhk Suh ( $\nabla$ ysksuh@gmail.com )

Seoul National University College of Medicine

Tae-Han Kim

Gyeongsang National University Changwon Hospital

\section{Yoon-Hee Choi}

Seoul National University Hospital

Jong-Ho Choi

Seoul National University Hospital

\section{Seong-Ho Kong}

Seoul National University College of Medicine

Do Joong Park

Seoul National University College of Medicine

Hyuk-Joon Lee

Seoul National University College of Medicine

\section{Han-Kwang Yang}

Seoul National University College of Medicine

\section{Research Article}

Keywords: gastric cancer, totally laparoscopic total gastrectomy, laparoscopy-assisted total gastrectomy, morbidity, quality of life, hemi-double stapling

Posted Date: May 13th, 2021

DOl: https://doi.org/10.21203/rs.3.rs-491793/v1

License: (9) This work is licensed under a Creative Commons Attribution 4.0 International License. Read Full License 


\section{Abstract}

Background. This study aimed to evaluate the surgical outcome and quality of life (QoL) of totally laparoscopic total gastrectomy (TLTG) compared with laparoscopy-assisted total gastrectomy (LATG) in patients with clinical stage I gastric cancer.

Methods. From 2012 to 2018, EGC patients who underwent TLTG ( $n=223)$, including the first case with intracorporeal hemi-double stapling, were matched to those who underwent LATG $(n=114)$ with extracorporeal circular stapling, using 2:1 propensity score matching (PSM). Prospectively collected morbidity was compared between the TLTG and LATG groups in conjunction with the learning curve. The European Organization for Research and Treatment of Cancer (EORTC) QoL questionnaires QLQ-C30, STO22, and OG25 were prospectively surveyed during postoperative 1 year for patient subgroups.

Results. After PSM, grade I pulmonary complication rate was lower in the TLTG group $(n=213)$ than in the LATG group ( $\mathrm{n}=111)(0.5 \%$ vs. $5.4 \%, P=0.007)$. Other complications were not different between the groups. The learning curve of TLTG was overcome at the $26^{\text {th }}$ case in terms of the comprehensive complication index. The TLTG group after learning curve showed lower grade I pulmonary complication rate than the matched LATG group ( $0.5 \%$ vs. $4.7 \%, P=0.024)$. Regarding postoperative QoL, the TLTG group $(\mathrm{n}=63)$ revealed less dysphagia $(P=0.028)$, pain $(P=0.028)$, eating restriction $(P=0.006)$, eating $(P=0.004)$, odynophagia $(P=0.023)$ than the LATG group $(n=21)$. Multivariate analyses for each $Q \circ$ item demonstrated that TLTG was the only common independent factor for better QoL.

Conclusions. TLTG reduced pulmonary complications and provided better QoL in dysphagia, pain, eating, odynophagia than LATG for patients with clinical stage I gastric cancer.

\section{Introduction}

The Korean national cancer screening program contributed to an increase in the diagnosis of early gastric cancer (EGC), reaching 61\% in 2014. In particular, the incidence of upper one-third EGC gradually increased from $11.2 \%$ in 1995 to $16.0 \%$ in 2014 , according to the Information Committee of Korean Gastric Cancer [1], [2] The global incidence of cardia cancer has also grown seven-fold over the past decades [3]. In the era of minimally invasive surgery, laparoscopy-assisted total gastrectomy (LATG) or totally laparoscopic total gastrectomy (TLTG) have been highlighted with the expectation of minimal invasiveness. TLTG has not been fully standardized yet due to the technical difficulty of intracorporeal esophagojejunostomy. Even a recent large prospective multicenter phase II trial (KLASS-03) reported acceptable postoperative morbidity and mortality for patients with clinical stage I gastric cancer, the procedures for esophagojejunostomies were not standardized yet [4].

Previous studies using those various surgical procedures reported the potential advantages of TLTG, such as less pain, less blood loss, and shorter operation time, than LATG [5-10]. Besides, upper abdominal pain interferes with diaphragmatic movement and subsequently worsens pulmonary complications, which can be the typical morbidity after TLTG or LATG [11-13]. However, level I evidence for these 
morbidities has not been established by a randomized critical trial yet, and a reasonable case matching study with a sufficient sample size also has not even been reported. On the other hand, evaluating the postoperative quality of life (QoL) may provide meaningful implications for minimally invasive surgery. Less adhesion after laparoscopic gastrointestinal surgery was reported to improve QoL such as global health status, reflux symptom, and appetite loss by enabling a comfortable diet with less pain and better peristalsis [14-17]. However, QoL after TLTG was rarely compared with that after LATG, especially at multiple time points after surgery [18].

This study aimed to evaluate and compare surgical outcomes and QoL of TLTG with those of LATG in patients with clinical stage I gastric cancer using propensity-score matching (PSM).

\section{Materials And Methods}

\section{Study design}

We reviewed the prospectively collected morbidity database of consecutive patients who underwent TLTG for clinical stage I gastric cancer between 2012 and 2018 at Seoul National University Hospital (SNUH). Clinical staging was evaluated by preoperative esophagogastroduodenoscopy, endoscopic ultrasonography and computed tomography. In this study, TLTG was defined as the case in which esophagojejunostomy was reconstructed intracorporeally, irrespective of intra- or extracorporeal jejunostomy. In SNUH, TLTG was performed since 2013, and four surgeons have gradually adopted TLTG according to the trend of minimal invasiveness demand, rather than separate indications for TLTG or LATG (Supplementary Figure S1). All TLTG cases, including the first starting case with intracorporeal esophagojejunostomy by using the hemi-double stapling technique (hDST) were enrolled in this study to elucidate the safe adoption of new laparoscopic surgical skill and minimize the selection bias. TLTGs with intracorporeal esophagojejunostomy other than hDST or reduced port laparoscopic total gastrectomies were excluded (Supplementary Figure S2).

Clinicopathologic data and other operative parameters were retrospectively reviewed. Each case from the TLTG group was 2:1 propensity score matched to control cases of the LATG group. The matching variables included age, sex, body mass index (BMI), combined organ resection, and pathological $\mathrm{T}$ and $\mathrm{N}$ stages. A propensity score of each patient was estimated by logistic regression (SPSS version 25; IBM Inc., Chicago, IL, USA) and matched nearest-neighbor value within a caliper 0.02 times the standard deviation of the estimated score. After PSM, the balance of covariates between TLTG and LATG group were evaluated by calculating the standardized mean difference. Detailed method for statistical analysis was described in supplementary methods.

\section{Surgical procedures}

Laparoscopic total gastrectomy was conducted with D1+ lymph node dissection according to the Korean practice guideline for gastric cancer and Japanese gastric cancer guidelines [19, 20]. 
For TLTG, a 3-4 cm laparotomy was made in the umbilicus or through the left lower port site after transecting the duodenum. The anvil head of the circular stapler (EEA, 25-4.8 mm, Covidien, Mansfield, MA, USA), with its rod knotted several times using a 2-0 Prolene, were brought into the peritoneal cavity. The distal esophagus was fastened tightly with umbilical tape (32 $\mathrm{mm}$ width, $15 \mathrm{~cm}$ length, Ethicon, USA) and stretched in the direction of left lower quadrant. Then, the anterior wall of the distal esophagus was opened along the circumferential direction. The prepared anvil was inserted through the esophagotomy site and advanced into the esophagus higher than the expected proximal resection margin. By piercing the needle through the medial side of the esophageal wall, a spike of the anvil rod could be retrieved outside. The esophagus was transected by the linear stapler with 60-mm AMT, a purple cartridge (Endo $\mathrm{GIA}^{\mathrm{TM}}$, Covidien, Mansfield, MA, USA) above the esophagotomy site. As a result, the anvil rod is located at the medial end of the staple line (Figure 1).

After the resected stomach was brought out through the mini-laparotomy, side-to side jejuno-jejunostomy was performed at approximately $40 \mathrm{~cm}$ distal to the expected esophagojejunostomy site using the linear stapler with 45- or 60-mm AVM, tan cartridge (Endo GIATM, Covidien). The circular stapler was inserted into the jejunal Roux limb, fastened with a rubber band to prevent slippage. Then, the Roux limb with the circular stapler was brought into the abdominal cavity, and pneumoperitoneum was reestablished. Under a secure laparoscopic view, the jejunal Roux limb was connected to the anvil, and intracorporeal anastomosis was finally performed. The jejunal stump was closed by the linear stapler with $60-\mathrm{mm}$ AVM, a tan cartridge.

For LATG, about $8.5 \mathrm{~cm}$ sized upper midline incision was made at the epigastrium [21]. Under the direct vision through the mini-laparotomy, a purse-string suture and device were applied to the distal esophagus, and the stomach was transected distal to the purse-string device. The anvil head of the circular stapler (EEA, 25-4.8 mm, Covidien, Mansfield, MA, USA) was inserted into the esophagus and the purse-string suture was secured to fasten the anvil rod. Then, the extracorporeal esophagojejunsotomy was performed with a $25 \mathrm{~mm}$ circular stapler through a mini-laparotomy incision. Extracorporeal side to side jejuno-jejunostomy was performed through the mini-laparotomy incision with a similar manner to jejunojejunostomy in TLTG.

\section{Surgical outcome and quality of life}

Complication data have been prospectively collected and recorded with the consensus of the entire gastrointestinal surgical team of SNUH through the weekly conference. General postoperative management including oral care, usage of prophylactic antibiotics, and pulmonary rehabilitation was the same over the study period. Morbidity and mortality were evaluated according to the Clavien-Dindo classification, and comprehensive complication index (CCl) calculated by the $\mathrm{CCl}$ formula (https://www.assessurgery.com/) [22]. Detailed methods for determining the learning curve based on cumulative sum score and evaluating the quality of life were described in supplementary methods.

\section{Results}




\section{Surgical outcome}

Before matching, the TLTG group $(n=223)$ and LATG group $(n=114)$ had no significant differences in baseline clinicopathologic variables (Table 1). After 2:1 PSM, the 213 patients in the TLTG group were matched to the 111 patients in the LATG group. The propensity scores, matching variables, and other remaining variables became highly balanced between TLTG and LATG groups (Supplementary Figure S3). In terms of oncological safety, the number of retrieved lymph nodes and the distribution of TNM stage was not significantly different between TLTG and LATG (Table 1). In addition, the number of retrieved lymph nodes per each station was not significantly different across all stations between TLTG and LATG (Supplementary Figure S4).

Regarding surgical complications within postoperative 1 month, grade I pulmonary complications of the TLTG group were significantly lower than those of the LATG group before ( $0.9 \%$ vs. $5.3 \%, P=0.020)$ and after matching ( $0.5 \%$ vs. $5.4 \%, P=0.007)$. However, the overall rate of pulmonary complications was not different between two groups before ( $10.8 \%$ vs. $12.3 \%, p=0.717)$ and after matching $(9.4 \%$ vs. $12.6 \%, p=$ 0.445). The other complications, including anastomosis-related complications, were not significantly different between the two groups before or after matching. Regarding complications detected between the postoperative 1 month and 1 year, the incidence and detection date of delayed stenosis of esophagojejunostomy were not different between the two groups before and after matching (Table 2).

\section{Learning curve for TLTG}

The CUSUM graph using the $\mathrm{CCl}$ showed two negatively sloping curve during the observation period with the trend line $(y=-0.3118 x+55.602)$ (Supplementary Figure S5a). In the first phase, the CUSUM score gradually increased and reached the first highest peak at case 26 (score, 118.00), then two more peak values at case 50 (score, 113.77) and case 73 (score, 80.77), and decreased until case 103 (score, -112.357). The TLTG group did not show clear decreasing pattern in operation time over chronological cases (Supplementary Figure S5b). We defined the $26^{\text {th }}$ case as a point of overcoming the learning curve, and rationales for this was described in Supplementary Table 1.

Table 3 presents the postoperative morbidity between the late TLTG group after overcoming the learning curve and the re-matched LATG group since 2012 when LATG was actively performed. The overall rate of grade I complication ( $2.1 \%$ vs $8.5 \%, P=0.016)$, especially pulmonary complication $(0.5 \%$ vs. $4.7 \%$, $P=0.024$ ), was still significantly lower in the late TLTG group than in the LATG group after matching. The overall rate of pulmonary complications was not different between two late groups $(9.0 \%$ vs. $11.3 \%$, $P=0.546$ ). Other complications, including anastomosis-related complications, were not different between the late TLTG and LATG groups before and after matching.

\section{Quality of Life}

The TLTG $(n=63)$ and LATG $(n=21)$ groups were matched to prospectively collected QoL data. The clinicopathologic characteristics and complications were not different between the two groups 
(Supplementary Table 2). During postoperative 1 year, the rates of STO22 dysphagia $(P=0.028)$, STO22 pain $(P=0.028)$, STO22 eating restriction $(P=0.006), 0 G 25$ eating $(P=0.004)$, and OG25 odynophagia $(P=0.023)$ were significantly lower in the TLTG group $(n=63)$ than in the LATG group $(n=21)$ (Figure 2a-e). Other QoL items of EORTC-C30, STO22, and OG25 questionnaires between the TLTG and LATG groups are presented in Supplementary Figure S6. For those five significant QoL questionnaires, ANCOVA at each three different time points (postoperative 3 months, 6 months, and 1 year) revealed that STO22 dysphagia at postoperative 6 months ( 15.55 vs. 31.26, $P<0.001$ ), STO22 pain at postoperative 3,6 and 12 months (20.64 vs. $34.51, P=0.031 ; 19.15$ vs. $32.09, P=0.006 ; 18.82$ vs. $30.15, P=0.002$ ), ST022 eating restriction at postoperative 6 months (20.50 vs. 30.61, $P=0.031), O G 25$ eating at postoperative 6 and 12 months ( 20.08 vs. $28.73, P=0.007 ; 20.75$ vs. $37.18, P=0.012)$, and $O G 25$ odynophagia at postoperative 6 months (13.82 vs. 28.82, $P=0.003$ ) were significantly better in the TLTG group than in LATG group, after controlling the confounding effects of preoperative QoL (Figure 2a-e). Multivariate linear regression for variables including age, sex, BMI, TLTG (vs. LATG), pT stage, pN stage, baseline QoL score, and the rate of overall complication $(\mathrm{CCl})$ revealed that TLTG was the only common independent risk factor for significantly better QoL at each different time point, after excluding all possible confounding factors (all $P<0.05$ ) (Table 4). For more robust validation of the role of TLTG, we used the anastomosis related complication and motility disorder as covariates for multivariate analysis, instead of $\mathrm{CCl}$ as overall complications. Still, TLTG remained as the only common independent risk factor for better QoL (Supplementary Table 3).

\section{Discussion}

This study successfully demonstrated the advantage of TLTG compared with matched LATG in terms of lower grade I pulmonary complication rate and better QoL of dysphagia, pain, or eating during postoperative 1 year. Retrospective studies cannot usually be sensitive enough to analyze parameters such as minor complications or changes in QoL and may provide false-negative or biased results. This study utilized prospectively collected complication data and QoL cohort, both of which had been recruited independently of the original purpose of this study. We believe that our study can provide less biased and more sensitive results than other unmatched retrospective studies.

The postoperative pulmonary complication was reported as one of the greatest risk factors for postoperative mortality in gastric cancer patients [12, 23, 24]. In addition, total gastrectomy was an independent risk factor for pulmonary complications following laparoscopic gastrectomy [13]. Previous meta-analysis comparing LATG with open TG reported that LATG was associated with a significant reduction in medical complications, but a contribution from respiratory complications was not significant [25]. Other retrospective study limitedly demonstrated the lower incidence of pulmonary complications in the LATG group than in the OTG group, only in patients aged over 65 [26]. On the other hand, previous studies comparing TLTG and LATG mainly focused on anastomotic complications, and rarely addressed issues with pulmonary complications [1-5]. Upper abdominal incision causes decreased pulmonary function more frequently than lower abdominal surgery $[11,27,28]$. The mini-laparotomy wounds of the LATG are inevitably larger and located closer to epigastrium than those of TLTG. In addition, the LATG 
group had a higher score of STO22 pain than the TLTG group (Figure 2b). The larger incisions in the epigastrium and worse pain score may explain the limited movement of the diaphragm and deep breathing, followed by a decreased pulmonary function in the LATG group.

This is the first study comparing QoL over consecutive multiple time points during the year after operation between TLTG and LATG groups. Previous studies reported better QoL scores of C30 pain and STO22 dysphagia in the TLTG group than in the LATG group, but only investigated the QoL at a single time point and did not include OG25, more sensitive in evaluating QoL after total gastrectomy [18, 29]. In this study, TLTG only determined a better QoL for dysphagia, eating, or odynophagia. DST without pursestring suture was first introduced in 1994 as an easier alternative technique to single stapling technique (SST), but has a risk of high postoperative anastomotic stenosis rate [30,31]. To overcome this limitation, hDST was proposed, but previous studies still reported high rates of stenosis (7.3\%-21\%) and leakage (4.9\%-9.9\%) [30, 32, 33]. Since 2013, SNUH started TLTG with intracorporeal hDST using needle-guided anvil fixation. Our institution standardized this technique with repeated discussion and consensus among surgeons from the first case, by which all complications were not different among operators $(P=0.947$, supplementary table 4). Many previous reports of hDST techniques revealed that it was difficult to tighten the entry hole of the anvil spike at the esophageal stump [32, 33]. On the other hand, the anvil spike located in the middle of the esophageal wall still might have a risk of double stapling across the efferent loop of the Roux limb [34]. As a simple modification, we pulled out the anvil in the medial esophageal wall using the guiding thread, which led to the smallest entry hole for the anvil spike, and secured hDST with a single stapling site completely toward the efferent loop and double stapling site toward the blind loop of the jejunal Roux-limb. In this study, the low rates of early and delayed anastomotic complications demonstrated the safety and efficacy of our modified hDST. In addition, the TLTG group with hDST showed better QoL of dysphagia and eating restriction than the LATG group. Adhesion after initial abdominal surgery occurs within the postoperative 1 year and may last for several years. [35-38]. Adhesion tissue were reported to contain nerve conducting pain stimuli [39]. Since, fixed adhesion can compromise the lumen of bowel, and filmy adhesion allowing movement between the bowel and surrounding structure can elicit nonobstructive abdominal pain, patients with peritoneal adhesion can manifest vague to highly distressing pain [40]. The unpredictability of abdominal pain caused by adhesions significantly impacts on a patient's emotions and social life, including fear for eating [41]. We assume that less exposure of the peritoneal cavity, especially the upper abdomen, may induce less adhesion around the anastomosis or provide better recovery of bowel movement [42-44]. Taken together, not only the possible different exposure of peritoneal cavity but also the different anastomotic technique may explain the different QoL in this study.

In this study, we analyzed the CUSUM and learning curve based on the $\mathrm{CCl}$, rather than operation time. In the past, standardizing multiple complications into a single variable seemed impossible due to the absence of adequate methods. However, through introducing $\mathrm{CCl}$, one representative complication index per patient can be estimated. To our knowledge, this is the first study to evaluate the learning curve using $\mathrm{CCl}$. Because $\mathrm{CCl}$ is directly related to the patient's outcome, this approach to the learning curve is more reasonable and intuitively understandable, than previous ones based on operation time. Our study can 
imply that simple effort to shorten the operation time may be less meaningful during the adoption and stabilization of a novel and complex surgical technique.

This study has some limitations. Firstly, since LATG and TLTG were performed in different time periods, there might be a discrepancy in laparoscopic surgical skills or chronologic changes in clinicopathologic factors between the TLTG and LATG groups. This time trend was inevitable when comparing old and new surgical techniques in retrospective analysis. To minimize this bias, we included all patients in the TLTG group from the first case, and all patients in the LATG group during the same period of TLTG for analysis. Besides, all surgeons at SNUH started performing TLTG in a similar period. Secondly, the sample size for QoL evaluation between TLTG and LATG was limited. In SNUH, an independent prospective cohort study was conducted to analyze only QoL, regardless of the purpose of the present study. Of these prospectively collected cohorts, we could separately selected 84 patients who met the inclusion criteria of the current study, not based on specific criteria or intentions. Therefore, the independence of QoL data can be the unbiased evidence for current study. Despite the small sample size of QoL data, this is the first study comparing QoL over consecutive multiple time points during the year after operation between TLTG and LATG groups. Considering that a small sample size usually has a risk of yielding false-negative or low sensitivity results, the significant difference in QoL between TLTG and LATG, even in the multivariate analysis, still can be valuable. However, large-scale prospective RCTs are necessary to validate more robust evidence for QoL differences.

In conclusion, TLTG with hDST were associated with reduced pulmonary complications and better QoL in terms of dysphagia, pain, eating, and odynophagia than LATG for patients with clinical stage I gastric cancer.

\section{Abbreviations}

QoL: quality of life; TLTG: Totally laparoscopic total gastrectomy; LATG: Laparoscopy-assisted total gastrectomy; PSM: propensity score matching; EORTC: European Organization for Research and Treatment of Cancer; EGC: Early gastric cancer; KLASS: Korean Laparoendoscopic Gastrointestinal Surgery Study; SNUH: Seoul National University Hospital; hDST: hemi-double stapling technique; BMI: Body mass index; CCl: Comprehensive complication index; SST: single stapling technique

\section{Declarations}

\section{Ethics approval and consent to participate}

All procedures followed were in accordance with the ethical standards of the responsible committee on human experimentation (institutional and national) and with the Helsinki Declaration of 1964 and later versions. This study was approved by the Institutional Review Board of Seoul National University Hospital (IRB number: H1802-031-919, H1406-108-590). The requirement for written informed consent was waived 
by the Institutional Review Board of Seoul National University Hospital, because of the retrospective nature of this study.

\section{Consent for publication}

Not applicable.

\section{Availability of data and materials}

The datasets generated and/or analyzed during the current study are not publicly available due to the governmental policy regarding the individual information, but are available from the corresponding author upon reasonable request.

\section{Conflicts of Interest}

Drs. S.-H. Park, Y.-S. Suh, T.-H. Kim, Y.-H. Choi, J.-H. Choi, S.-H. Kong, D. J. Park, H.-J. Lee, and H.-K. Yang have no conflicts of interest or financial ties to disclose.

\section{Funding}

This study was supported by a research grant of Seoul National University Hospital (grant number 042018-3040). The funder had no role in study design, data analysis, or writing of this article.

\section{Author contributions}

SHP, YSS and HKY designed the study.

SHP, YSS, THK YHC, and JHC analyzed and interpreted data.

SHP and YSS drafted the article.

SHP, YSS, SHK, DJP, HJL and HKY critically revised the article for important intellectual content.

All authors confirmed that the content has not been published elsewhere and does not overlap with or duplicate their published work.

\section{Acknowledgments}

Not applicable.

\section{References}

1. Information Committee of Korean Gastric Cancer, Association. Korean Gastric Cancer Association nationwide survey on gastric cancer in 2014. J Gastric Cancer. 2016;16(3):131-140. 
2. Jeong O, Park YK. Clinicopathological features and surgical treatment of gastric cancer in South Korea: the results of 2009 nationwide survey on surgically treated gastric cancer patients. J Gastric Cancer. 2011;11(2):69-77.

3. Rawla, P. and A. Barsouk. Epidemiology of gastric cancer: global trends, risk factors and prevention. Prz Gastroenterol. 2019;14(1):26-38.

4. Hyung WJ, Yang HK, Han SU, Lee YJ, Park JM, Kim JJ, et al. A feasibility study of laparoscopic total gastrectomy for clinical stage I gastric cancer: a prospective multicenter phase II clinical trial, KLASS 03. Gastric Cancer. 2019;22(1):214-222.

5. Chen K, Pan Y, Cai JQ, Wu D, Yan JF, Chen DW, et al. Totally laparoscopic versus laparoscopicassisted total gastrectomy for upper and middle gastric cancer: a single-unit experience of 253 cases with meta-analysis. World J Surg Oncol. 2016;14:96.

6. Gong CS, Kim BS, Kim HS. Comparison of totally laparoscopic total gastrectomy using an endoscopic linear stapler with laparoscopic-assisted total gastrectomy using a circular stapler in patients with gastric cancer: a single-center experience. World J Gastroenterol. 2017;23(48):85538561.

7. Ito $\mathrm{H}$, Inoue $\mathrm{H}, \mathrm{Odaka} \mathrm{N}$, Satodate $\mathrm{H}$, Onimaru $\mathrm{M}$, Ikeda $\mathrm{H}$, et al. Evaluation of the safety and efficacy of esophagojejunostomy after totally laparoscopic total gastrectomy using a trans-orally inserted anvil: a single-center comparative study. Surg Endosc. 2014;28(6):1929-1935.

8. Jung YJ, Kim DJ, Lee JH, Kim W. Safety of intracorporeal circular stapling esophagojejunostomy using trans-orally inserted anvil (OrVil) following laparoscopic total or proximal gastrectomy comparison with extracorporeal anastomosis. World J Surg Oncol. 2013;11:209.

9. Umemura A, Koeda K, Sasaki A, Fujiwara H, Kimura Y, Iwaya T, et al. Totally laparoscopic total gastrectomy for gastric cancer: literature review and comparison of the procedure of esophagojejunostomy. Asian J Surg. 2015;38(2):102-112.

10. Yamamoto M, Kawano H, Yamaguchi S, Egashira A, Minami K, Morita M, et al. Technical and survival risks associated with esophagojejunostomy by laparoscopic total gastrectomy for gastric carcinoma. Surg Laparosc Endosc Percutan Tech. 2017;27(3):197-202.

11. Woo J, Lee JH, Shim KN, Jung HK, Lee HM, Lee HK et al. Does the difference of invasiveness between totally laparoscopic distal gastrectomy and laparoscopy-assisted distal gastrectomy lead to a difference in early surgical outcomes? a prospective randomized trial. Ann Surg Oncol. 2015;22(6):1836-1843.

12. Gertsen EC, Goense L, Brenkman HJF, van Hillegersberg R, Ruurda JP; Dutch Upper Gastrointestinal Cancer Audit (DUCA) group. Identification of the clinically most relevant postoperative complications after gastrectomy: a population-based cohort study. Gastric Cancer. 2020;23(2):339-348.

13. Ntutumu R, Liu H, Zhen L, Hu YF, Mou TY, Lin T et al. Risk factors for pulmonary complications following laparoscopic gastrectomy: a single-center study. Medicine (Baltimore). 2016;95(32):e4567.

14. Yasuda K, Shiraishi N, Etoh T, Shiromizu A, Inomata M, Kitano S. Long-term quality of life after laparoscopy-assisted distal gastrectomy for gastric cancer. Surg Endosc. 2007;21(12):2150-2153. 
15. Kim YW, Baik YH, Yun YH, Nam BH, Kim DH, Choi IJ, et al. Improved quality of life outcomes after laparoscopy-assisted distal gastrectomy for early gastric cancer: results of a prospective randomized clinical trial. Ann Surg. 2008;248(5):721-727.

16. Kawamura H, Takahashi N, Homma S, Minagawa N, Shibasaki S, Takahashi M, et al. Assessment of postoperative symptoms after laparoscopy-assisted distal gastrectomy for stage I gastric cancer. Int Surg. 2014;99(5):645-649.

17. Carvajal SH, Mulvihill SJ. Postgastrectomy syndromes: dumping and diarrhea. Gastroenterol Clin North Am. 1994;23(2):261-279.

18. Huang ZN, Huang CM, Zheng CH, Li P, Xie JW, Wang JB, et al. Digestive tract reconstruction using isoperistaltic jejunum-later-cut overlap method after totally laparoscopic total gastrectomy for gastric cancer: short-term outcomes and impact on quality of life. World J Gastroenterol. 2017;23(39):71297138.

19. Guideline Committee of the Korean Gastric Cancer Association (KGCA), Development Working Group \& Review Panel. Korean practice guideline for gastric cancer 2018: an evidence-based, multidisciplinary approach. J Gastric Cancer. 2019;19(1):1-48.

20. Japanese Gastric Cancer Association. Japanese gastric cancer treatment guidelines 2014 (ver. 4). Gastric Cancer. 2017;20(1):1-19.

21. Yang HK, Hyung WJ, Han SU, Lee YJ, Park JM, Cho GS, et al. Comparison of surgical outcomes among different methods of esophagojejunostomy in laparoscopic total gastrectomy for clinical stage I proximal gastric cancer: results of a single-arm multicenter phase II clinical trial in Korea, KLASS 03. Surg Endosc. 2020 Mar 6. doi: 10.1007/s00464-020-07480-0.

22. Dindo D, Demartines N, Clavien PA. Classification of surgical complications: a new proposal with evaluation in a cohort of 6336 patients and results of a survey. Ann Surg. 2004;240(2):205-213.

23. Kim SM, Youn HG, An JY, Choi YY, Noh SH, Oh SJ, et al. Comparison of open and laparoscopic gastrectomy in elderly patients. J Gastrointest Surg. 2018;22(5):785-791.

24. Tu RH, Lin JX, Li P, Xie JW, Wang JB, Lu J, et al. Prognostic significance of postoperative pneumonia after curative resection for patients with gastric cancer. Cancer Med. 2017;6(12):2757-2765.

25. Chen K, Xu XW, Zhang RC, Pan Y, Wu D, Mou YP. Systematic review and meta-analysis of laparoscopy-assisted and open total gastrectomy for gastric cancer. World J Gastroenterol. 2013;19(32):5365-76.

26. Liu D, Liang L, Liu L, Zhu Z, Liu S, Hu L, et al. Short-term outcomes and prognosis of laparoscopyassisted total gastrectomy in elderly patients with stomach cancer. Surg Endosc. 2020;34(12):54285438.

27. Ford GT, Rosenal TW, Clergue F, Whitelaw WA. Respiratory physiology in upper abdominal surgery. Clin Chest Med. 1993;14(2):237-252.

28. Desai PM. Pain management and pulmonary dysfunction. Crit Care Clin. 1999;15(1):151-66, vii.

29. Lee JH, Lee HJ, Choi YS, Kim TH, Huh YJ, Suh YS, et al. Postoperative quality of life after total gastrectomy compared with partial gastrectomy: Iongitudinal evaluation by European Organization 
for Research and Treatment of Cancer-OG25 and STO22. J Gastric Cancer. 2016;16(4):230-239.

30. Zuiki T, Hosoya Y, Kaneda Y, Kurashina K, Saito S, Ui T, et al. Stenosis after use of the double-stapling technique for reconstruction after laparoscopy-assisted total gastrectomy. Surg Endosc. 2013;27(10):3683-3689.

31. Tejero Cebrián E, Ratia Giménez T, Fernández Fernández L, Tieso Herreros A, Jorge Sanchez E. Double-stapling technique for mechanical circular oesophagojejunal anastomosis after total gastrectomy. Br J Surg. 1994;81(3):408-409.

32. Amisaki M, Kihara K, Endo K, Suzuki K, Nakamura S, Sawata T, et al. Comparison of single-stapling and hemi-double-stapling methods for intracorporeal esophagojejunostomy using a circular stapler after totally laparoscopic total gastrectomy. Surg Endosc. 2016;30(7):2994-3000.

33. Kosuga T, Hiki N, Nunobe S, Ohashi M, Kubota T, Kamiya S, et al. Does the single-stapling technique for circular-stapled esophagojejunostomy reduce anastomotic complications after laparoscopic total gastrectomy? Ann Surg Oncol. 2015;22(11):3606-3612.

34. Omori T, Moon JH, Yamamoto K, Yanagimoto Y, Sugimura K, Miyata H, et al. A modified efficient purse-string stapling technique (mEST) that uses a new metal rod for intracorporeal esophagojejunostomy in laparoscopic total gastrectomy. Transl Gastroenterol Hepatol. 2017;2:61.

35. Boland GM, Weigel RJ. Formation and prevention of postoperative abdominal adhesions. J Surg Res. 2006;132(1):3-12.

36. Kim SG, Song KY, Lee HH, Kim EY, Lee JH, Jeon HM, et al. Efficacy of an antiadhesive agent for the prevention of intra-abdominal adhesions after radical gastrectomy: A prospective randomized, multicenter trial. Medicine (Baltimore). 2019;98(19):e15141.

37. Parker MC. Epidemiology of adhesions: the burden. Hosp Med. 2004;65(6):330-6.

38. Sakari T, Christersson M, Karlbom U. Mechanisms of adhesive small bowel obstruction and outcome of surgery; a population-based study. BMC Surg. 2020;20(1):62.

39. Sulaiman H, Gabella G, Davis MSc C, Mutsaers SE, Boulos P, Laurent GJ, et al. Presence and distribution of sensory nerve fibers in human peritoneal adhesions. Ann Surg. 2001;234(2):256-61.

40. Demco L. Pain mapping of adhesions. J Am Assoc Gynecol Laparosc. 2004;11(2):181-3.

41. Tabibian N, Swehli E, Boyd A, Umbreen A, Tabibian JH. Abdominal adhesions: A practical review of an often overlooked entity. Ann Med Surg (Lond). 2017;15:9-13.

42. Choi SJ, Gong CS, Kim BS, Kim So, Kim HS. Clinical outcomes of totally laparoscopic total gastrectomy versus open total gastrectomy for remnant gastric cancer. J Minim Invasive Surg. 2019;22(1):29-38.

43. Ikeda O, Sakaguchi Y, Aoki Y, Harimoto N, Taomoto J, Masuda T, et al. Advantages of totally laparoscopic distal gastrectomy over laparoscopically assisted distal gastrectomy for gastric cancer. Surg Endosc. 2009;23(10):2374-2379.

44. Kim BS, Yook JH, Choi YB, Kim KC, Kim MG, Kim TH, et al. Comparison of early outcomes of intracorporeal and extracorporeal gastroduodenostomy after laparoscopic distal gastrectomy for 
gastric cancer. J Laparoendosc Adv Surg Tech A. 2011;21(5):387-391.

\section{Tables}

Table 1. Clinicopathologic characteristics between the TLTG group and LATG group before and after 2:1 PSM. 


\begin{tabular}{|c|c|c|c|c|c|c|}
\hline \multirow[t]{3}{*}{ Variables } & \multicolumn{2}{|c|}{ Before matching } & \multirow{3}{*}{$\begin{array}{l}P \\
\text { value }\end{array}$} & \multicolumn{2}{|c|}{ After matching } & \multirow{3}{*}{$\begin{array}{l}P \\
\text { value }\end{array}$} \\
\hline & TLTG & LATG & & TLTG & LATG & \\
\hline & $(n=223)$ & $(n=114)$ & & $(n=213)$ & $(n=111)$ & \\
\hline Age (years) & $\begin{array}{l}61.6 \pm \\
11.1\end{array}$ & $\begin{array}{l}59.5 \pm \\
11.0\end{array}$ & 0.090 & $\begin{array}{l}61.4 \pm \\
10.7\end{array}$ & $\begin{array}{l}59.8 \pm \\
10.7\end{array}$ & 0.203 \\
\hline Sex & & & 0.200 & & & 0.297 \\
\hline Male & $\begin{array}{l}166 \\
(74.4)\end{array}$ & $77(67.5)$ & & $\begin{array}{l}158 \\
(74.2)\end{array}$ & $76(68.5)$ & \\
\hline Female & $57(25.6)$ & $37(32.5)$ & & $55(25.8)$ & $35(31.5)$ & \\
\hline Body mass index $\left(\mathrm{kg} / \mathrm{m}^{2}\right)$ & $24.2 \pm 2.9$ & $24.1 \pm 3.3$ & 0.960 & $24.2 \pm 2.9$ & $24.1 \pm 3.3$ & 0.665 \\
\hline Combined resection & & & 0.295 & & & 0.574 \\
\hline None & $\begin{array}{l}195 \\
(87.4)\end{array}$ & $\begin{array}{l}106 \\
(93.0)\end{array}$ & & $\begin{array}{l}192 \\
(90.1)\end{array}$ & $\begin{array}{l}103 \\
(92.8)\end{array}$ & \\
\hline Gallbladder & $25(11.2)$ & $7(6.1)$ & & $21(9.4)$ & $7(6.3)$ & \\
\hline Spleen & $3(1.3)$ & $1(0.9)$ & & $1(0.5)$ & $1(0.9)$ & \\
\hline Tumor size $(\mathrm{mm})$ & $3.4 \pm 1.8$ & $3.2 \pm 1.9$ & 0.497 & $3.3 \pm 1.7$ & $3.2 \pm 1.9$ & 0.595 \\
\hline $\begin{array}{l}\text { Proximal resected margin } \\
(\mathrm{cm})\end{array}$ & $2.6 \pm 2.2$ & $2.7 \pm 2.3$ & 0.799 & $2.6 \pm 2.2$ & $2.7 \pm 2.4$ & 0.702 \\
\hline Mean retrieved lymph nodes & $\begin{array}{l}46.2 \pm \\
18.7\end{array}$ & $\begin{array}{l}47.2 \pm \\
15.8\end{array}$ & 0.603 & $\begin{array}{l}46.8 \pm \\
18.6\end{array}$ & $\begin{array}{l}47.2 \pm \\
15.6\end{array}$ & 0.827 \\
\hline $\begin{array}{l}\text { Number of metastatic lymph } \\
\text { nodes }\end{array}$ & $0.8 \pm 2.3$ & $0.6 \pm 2.5$ & 0.578 & $0.7 \pm 2.2$ & $0.6 \pm 2.5$ & 0.880 \\
\hline $\mathrm{R} 0$ resection & $223(100)$ & $114(100)$ & - & $213(100)$ & $111(100)$ & - \\
\hline $\begin{array}{l}\text { Number of patients } \\
\text { transfused }\end{array}$ & $2(0.9)$ & $1(0.9)$ & 0.985 & $1(0.5)$ & $1(0.9)$ & 0.638 \\
\hline Operation time (minutes) & $\begin{array}{l}267.3 \pm \\
50.3\end{array}$ & $\begin{array}{l}277.6 \pm \\
60.5\end{array}$ & 0.118 & $\begin{array}{l}266.1 \pm \\
49.5\end{array}$ & $\begin{array}{l}278.5 \pm \\
61.0\end{array}$ & 0.066 \\
\hline Hospital stays & $11.9 \pm 8.0$ & $10.9 \pm 6.9$ & 0.216 & $11.8 \pm 6.7$ & $10.8 \pm 6.7$ & 0.222 \\
\hline pT category & & & 0.201 & & & 0.274 \\
\hline pT1 & $\begin{array}{l}146 \\
(65.5)\end{array}$ & 85 (74.6) & & $\begin{array}{l}144 \\
(67.6)\end{array}$ & $82(73.9)$ & \\
\hline pT2 & 44 (19.7) & 15 (13.2) & & $41(19.2)$ & $15(13.5)$ & \\
\hline pT3 & 25 (11.2) & $8(7.0)$ & & $22(10.3)$ & $8(7.2)$ & \\
\hline pT4 & $8(3.6)$ & $6(5.3)$ & & $6(2.8)$ & $6(5.4)$ & \\
\hline & & Page $14 / 23$ & & & & \\
\hline
\end{tabular}




\begin{tabular}{|c|c|c|c|c|c|c|}
\hline pN category & & & 0.250 & & & 0.413 \\
\hline pNO & $\begin{array}{l}177 \\
(79.4)\end{array}$ & $99(86.8)$ & & $\begin{array}{l}171 \\
(81.2)\end{array}$ & $96(86.5)$ & \\
\hline $\mathrm{pN} 1$ & $22(9.9)$ & $6(5.3)$ & & $20(9.4)$ & $6(5.4)$ & \\
\hline $\mathrm{pN} 2$ & $18(8.1)$ & $5(4.4)$ & & $15(7.0)$ & $5(4.5)$ & \\
\hline pN3 & $6(2.7)$ & $4(3.5)$ & & $5(2.3)$ & $4(3.6)$ & \\
\hline TNM stage* & & & 0.497 & & & 0.741 \\
\hline Stage I & $\begin{array}{l}174 \\
(78.0)\end{array}$ & 95 (83.3) & & $\begin{array}{l}169 \\
(79.3)\end{array}$ & $92(82.9)$ & \\
\hline Stage II & $29(13.0)$ & $12(10.5)$ & & $27(12.7)$ & $12(10.8)$ & \\
\hline Stage III & $20(9.0)$ & $7(6.1)$ & & $17(8.0)$ & $7(6.3)$ & \\
\hline Stage IV & $0(0)$ & $0(0)$ & & $0(0)$ & $0(0)$ & \\
\hline
\end{tabular}

*TNM stage according to AJCC, the $7^{\text {th }}$ edition.

Abbreviations: TLTG = totally laparoscopic total gastrectomy; LATG = laparoscopy-assisted total gastrectomy; PSM = propensity score matching.

Table 2. Postoperative complications between the TLTG group and LATG group before and after 2:1 PSM. 


\begin{tabular}{|c|c|c|c|c|c|c|c|}
\hline \multicolumn{2}{|c|}{ Variables } & \multicolumn{2}{|c|}{ Before matching } & \multirow{3}{*}{$\begin{array}{l}P \\
\text { value }\end{array}$} & \multicolumn{2}{|c|}{ After matching } & \multirow{3}{*}{$\begin{array}{l}P \\
\text { value }\end{array}$} \\
\hline & & \multirow{2}{*}{$\begin{array}{c}\text { TLTG } \\
(n= \\
223)\end{array}$} & \multirow{2}{*}{$\begin{array}{l}\text { LATG } \\
(n= \\
114)\end{array}$} & & TLTG & LATG & \\
\hline & & & & & $\begin{array}{l}(n= \\
213)\end{array}$ & $\begin{array}{l}(n= \\
111)\end{array}$ & \\
\hline \multicolumn{2}{|c|}{ Overall complication: $\mathrm{n}(\%)$} & $\begin{array}{l}61 \\
(27.4)\end{array}$ & $\begin{array}{l}33 \\
(28.9)\end{array}$ & 0.798 & $\begin{array}{l}58 \\
(26.3)\end{array}$ & $\begin{array}{l}32 \\
(28.8)\end{array}$ & 0.693 \\
\hline \multicolumn{2}{|c|}{ Major complication ( $\geq$ grade IIla) } & $\begin{array}{l}26 \\
(11.7)\end{array}$ & $\begin{array}{l}13 \\
(11.4)\end{array}$ & 0.945 & $\begin{array}{l}24 \\
(11.3)\end{array}$ & $\begin{array}{l}13 \\
(11.7)\end{array}$ & 0.905 \\
\hline \multirow{2}{*}{\multicolumn{2}{|c|}{$\begin{array}{l}\text { Comprehensive complication } \\
\text { index } \\
\text { (median, range) }\end{array}$}} & $\begin{array}{l}7.1(0- \\
60.2)\end{array}$ & $\begin{array}{l}6.3(0- \\
40.5)\end{array}$ & 0.967 & $\begin{array}{l}6.9(0- \\
60.2)\end{array}$ & $\begin{array}{l}6.3(0- \\
40.5)\end{array}$ & 0.811 \\
\hline & & & & & & & \\
\hline \multicolumn{2}{|c|}{ Hospital stay } & $\begin{array}{l}11.9 \pm \\
8.0\end{array}$ & $\begin{array}{l}10.9 \pm \\
6.9\end{array}$ & 0.216 & $\begin{array}{l}11.8 \pm \\
6.7\end{array}$ & $\begin{array}{l}10.8 \pm \\
6.7\end{array}$ & 0.222 \\
\hline \multicolumn{8}{|c|}{$\begin{array}{l}\text { Complication detected within } 1 \\
\text { month }\end{array}$} \\
\hline \multirow[t]{7}{*}{ Grade I } & Wound & $0(0)$ & $2(1.8)$ & 0.114 & $0(0)$ & $2(1.8)$ & 0.117 \\
\hline & Fluid collection & $3(1.3)$ & $1(0.9)$ & 0.707 & $3(1.4)$ & $1(0.9)$ & 0.695 \\
\hline & Luminal bleeding & $0(0)$ & $1(0.9)$ & 0.338 & $0(0)$ & $1(0.9)$ & 0.343 \\
\hline & Motility disorder & $2(0.9)$ & $0(0)$ & 0.551 & $2(0.9)$ & $0(0)$ & 0.548 \\
\hline & Ischemia & $1(0.4)$ & $0(0)$ & 0.474 & $1(0.5)$ & $0(0)$ & 0.470 \\
\hline & Pulmonary & $2(0.9)$ & $6(5.3)$ & 0.020 & $1(0.5)$ & $6(5.4)$ & 0.007 \\
\hline & Other systemic & $3(1.3)$ & $2(1.8)$ & 0.769 & $3(1.4)$ & $2(1.8)$ & 0.785 \\
\hline \multirow[t]{9}{*}{ Grade II } & Fluid collection & $9(4.0)$ & $2(1.8)$ & 0.345 & $9(4.2)$ & $2(1.8)$ & 0.343 \\
\hline & $\begin{array}{l}\text { Intraabdominal } \\
\text { bleeding }\end{array}$ & $1(0.4)$ & $0(0)$ & 0.474 & $1(0.5)$ & $0(0)$ & 0.470 \\
\hline & Luminal bleeding & $1(0.4)$ & $1(0.9)$ & 0.628 & $1(0.5)$ & $1(0.9)$ & 0.638 \\
\hline & Stenosis (EJ) & $0(0)$ & $2(1.8)$ & 0.114 & $0(0)$ & $2(1.8)$ & 0.117 \\
\hline & Motility disorder & $2(0.9)$ & $1(0.9)$ & 0.985 & $2(0.9)$ & $1(0.9)$ & 0.973 \\
\hline & $\begin{array}{l}\text { Anastomosis site } \\
\text { leakage }\end{array}$ & $4(1.8)$ & $2(1.8)$ & 0.979 & $4(1.9)$ & $1(0.9)$ & 0.664 \\
\hline & Other fistula & $0(0)$ & $1(0.9)$ & 0.338 & $0(0)$ & $1(0.9)$ & 0.343 \\
\hline & Ischemia & $1(0.4)$ & $0(0)$ & 0.474 & $1(0.5)$ & $0(0)$ & 0.470 \\
\hline & Pulmonary & $12(5.4)$ & $4(3.3)$ & 0.592 & $10(4.7)$ & $4(3.6)$ & 0.778 \\
\hline
\end{tabular}




\begin{tabular}{|c|c|c|c|c|c|c|c|}
\hline & Other systemic & $8(3.6)$ & $4(3.5)$ & 0.971 & $8(3.8)$ & $4(3.6)$ & 0.945 \\
\hline \multirow[t]{8}{*}{ Grade IIla } & Wound & $2(0.9)$ & $3(2.6)$ & 0.341 & $2(0.9)$ & $3(2.7)$ & 0.343 \\
\hline & fluid collection & $12(5.4)$ & $4(3.5)$ & 0.592 & $11(5.1)$ & $4(3.6)$ & 0.592 \\
\hline & $\begin{array}{l}\text { Intraabdominal } \\
\text { bleeding }\end{array}$ & $1(0.4)$ & $0(0)$ & 0.474 & $1(0.5)$ & $0(0)$ & 0.470 \\
\hline & Stenosis & $1(0.4)$ & $0(0)$ & 0.474 & $1(0.5)$ & $0(0)$ & 0.470 \\
\hline & Motility disorder & $1(0.4)$ & $0(0)$ & 0.474 & $1(0.5)$ & $0(0)$ & 0.470 \\
\hline & $\begin{array}{l}\text { Anastomosis site } \\
\text { leakage }\end{array}$ & $5(2.2)$ & $1(0.9)$ & 0.668 & $5(2.3)$ & $1(0.9)$ & 0.668 \\
\hline & Pulmonary & $6(2.7)$ & $2(1.8)$ & 0.722 & $5(2.3)$ & $2(1.8)$ & 0.749 \\
\hline & Other systemic & $1(0.4)$ & $0(0)$ & 0.474 & $1(0.5)$ & $0(0)$ & 0.470 \\
\hline \multirow[t]{2}{*}{ Grade IIIb } & Wound & $2(0.9)$ & $1(0.9)$ & 0.985 & $2(0.9)$ & $1(0.9)$ & 0.973 \\
\hline & Motility disorder & $0(0)$ & $1(0.9)$ & 0.338 & $0(0)$ & $1(0.9)$ & 0.343 \\
\hline \multirow[t]{2}{*}{ Grade IVa } & $\begin{array}{l}\text { Intraabdominal } \\
\text { bleeding }\end{array}$ & $1(0.4)$ & $0(0)$ & 0.474 & $1(0.5)$ & $0(0)$ & 0.470 \\
\hline & Pulmonary & $2(0.9)$ & $0(0)$ & 0.551 & $1(0.5)$ & $0(0)$ & 0.470 \\
\hline Grade IVb & $\begin{array}{l}\text { Intraabdominal } \\
\text { bleeding }\end{array}$ & $1(0.4)$ & $0(0)$ & 0.474 & $1(0.5)$ & $0(0)$ & 0.470 \\
\hline \multicolumn{8}{|c|}{ Complication detected from 1 month to 1 year } \\
\hline & $\begin{array}{l}\text { Delayed EJ stenosis } \\
\text { (total no.) }\end{array}$ & $14(6.3)$ & $6(5.3)$ & 0.811 & $14(6.6)$ & $6(5.4)$ & 0.810 \\
\hline & $\begin{array}{l}\text { Delayed EJ stenosis } \\
\text { ( } \geq \text { grade IIla) }\end{array}$ & $7(3.1)$ & $5(4.4)$ & 0.549 & $7(3.3)$ & $5(4.5)$ & 0.553 \\
\hline & $\begin{array}{l}\text { Detected period for } \\
\text { (Days) }\end{array}$ & $\begin{array}{l}76.8 \pm \\
22.0\end{array}$ & $\begin{array}{l}74.2 \pm \\
12.7\end{array}$ & 0.743 & $\begin{array}{l}76.8 \pm \\
22.0\end{array}$ & $\begin{array}{l}74.2 \pm \\
12.7\end{array}$ & 0.743 \\
\hline
\end{tabular}

Abbreviations: TLTG = totally laparoscopic total gastrectomy; LATG = laparoscopy-assisted total gastrectomy; $\mathrm{PSM}$ = propensity score matching; $\mathrm{EJ}$ = esophagojejunostomy

Table 3. Postoperative complications between the late TLTG and LATG groups before and after 2:1 PSM. 


\begin{tabular}{|c|c|c|c|c|c|c|}
\hline \multirow[t]{2}{*}{ Variables } & \multicolumn{2}{|c|}{ Before matching } & \multirow{2}{*}{$\begin{array}{l}P \\
\text { value }\end{array}$} & \multicolumn{2}{|c|}{ After matching } & \multirow{2}{*}{$\begin{array}{l}P \\
\text { value }\end{array}$} \\
\hline & $\begin{array}{l}\text { late TLTG } \\
\text { after } 26^{\text {th }} \\
\text { case } \\
(\mathrm{n}=197)\end{array}$ & $\begin{array}{l}\text { LATG } \\
(n= \\
114)\end{array}$ & & $\begin{array}{l}\text { late } \\
\text { TLTG } \\
\text { after } 26^{\text {th }} \\
\text { case } \\
(\mathrm{n}=188)\end{array}$ & $\begin{array}{l}\text { LATG } \\
(n= \\
106)\end{array}$ & \\
\hline Overall complication: n (\%) & $48(24.4)$ & $\begin{array}{l}33 \\
(28.9)\end{array}$ & 0.422 & $44(23.4)$ & $\begin{array}{l}30 \\
(28.3)\end{array}$ & 0.401 \\
\hline Major complication ( $\geq$ grade IIla) & $23(11.7)$ & $\begin{array}{l}13 \\
(11.4)\end{array}$ & 0.942 & $22(11.7)$ & $\begin{array}{l}12 \\
(11.3)\end{array}$ & 0.922 \\
\hline $\begin{array}{l}\text { Comprehensive complication index } \\
\text { (median, range) }\end{array}$ & $\begin{array}{l}6.5(0- \\
60.2)\end{array}$ & $\begin{array}{l}6.3(0- \\
40.5)\end{array}$ & 0.553 & $\begin{array}{l}6.5(0- \\
60.2)\end{array}$ & $\begin{array}{l}6.3(0- \\
40.5)\end{array}$ & 0.521 \\
\hline Hospital stays & $\begin{array}{l}11.5 \pm \\
7.5\end{array}$ & $\begin{array}{l}10.9 \pm \\
6.9\end{array}$ & 0.461 & $\begin{array}{l}11.1 \pm \\
7.1\end{array}$ & $\begin{array}{l}11.9 \pm \\
10.1\end{array}$ & 0.422 \\
\hline \multicolumn{7}{|l|}{$\begin{array}{l}\text { Complication detected within } 1 \\
\text { month }\end{array}$} \\
\hline Grade I & $6(3.0)$ & $\begin{array}{l}10 \\
(8.8)\end{array}$ & 0.034 & $4(2.1)$ & $9(8.5)$ & 0.016 \\
\hline Wound & $0(0)$ & $2(1.8)$ & 0.134 & $0(0)$ & $2(1.9)$ & 0.129 \\
\hline Fluid collection & $0(0)$ & $1(0.9)$ & 0.367 & $0(0)$ & $1(0.9)$ & 0.361 \\
\hline Luminal bleeding & $0(0)$ & $1(0.9)$ & 0.367 & $0(0)$ & $1(0.9)$ & 0.361 \\
\hline Motility disorder & $1(0.5)$ & $0(0)$ & 0.446 & $1(0.5)$ & $0(0)$ & 0.452 \\
\hline Ischemia & $1(0.5)$ & $0(0)$ & 0.446 & $0(0)$ & $0(0)$ & - \\
\hline Pulmonary & $2(1.0)$ & $6(5.3)$ & 0.055 & $1(0.5)$ & $5(4.7)$ & 0.024 \\
\hline Other systemic & $1(0.5)$ & $2(1.8)$ & 0.557 & $1(0.5)$ & $2(1.9)$ & 0.296 \\
\hline Grade II & $25(12.7)$ & $\begin{array}{l}14 \\
(12.3)\end{array}$ & 0.916 & $24(12.8)$ & $\begin{array}{l}13 \\
(12.3)\end{array}$ & 0.901 \\
\hline Fluid collection & $6(3.0)$ & $2(1.8)$ & 0.715 & $6(3.2)$ & $2(1.9)$ & 0.715 \\
\hline Intraabdominal bleeding & $1(0.5)$ & $0(0)$ & 0.446 & $1(0.5)$ & $0(0)$ & 0.452 \\
\hline Luminal bleeding & $0(0)$ & $1(0.9)$ & 0.367 & $0(0)$ & $1(0.9)$ & 0.361 \\
\hline Stenosis (EJ) & $0(0)$ & $2(1.8)$ & 0.134 & $0(0)$ & $2(1.9)$ & 0.129 \\
\hline Motility disorder & $1(0.5)$ & $1(0.9)$ & 0.694 & $1(0.5)$ & $1(0.9)$ & 0.680 \\
\hline Anastomosis site leakage & $3(1.5)$ & $2(1.8)$ & 0.876 & $3(1.6)$ & $2(1.9)$ & 0.853 \\
\hline Other fistulas & $0(0)$ & $1(0.9)$ & 0.367 & $0(0)$ & $1(0.9)$ & 0.361 \\
\hline
\end{tabular}




\begin{tabular}{|c|c|c|c|c|c|c|}
\hline Ischemia & $1(0.5)$ & $0(0)$ & 0.446 & $1(0.5)$ & $0(0)$ & 0.452 \\
\hline Pulmonary & $9(4.6)$ & $4(3.5)$ & 0.774 & $9(4.8)$ & $3(2.8)$ & 0.547 \\
\hline Other systemic & $7(3.6)$ & $4(3.5)$ & 0.984 & $7(3.7)$ & $4(3.8)$ & 0.983 \\
\hline Grade IIla & $22(11.2)$ & $\begin{array}{l}10 \\
(8.8)\end{array}$ & 0.565 & $21(11.2)$ & $9(8.5)$ & 0.550 \\
\hline Wound & $2(1.0)$ & $3(2.6)$ & 0.360 & $2(1.1)$ & $2(1.9)$ & 0.621 \\
\hline fluid collection & $11(5.6)$ & $4(3.5)$ & 0.585 & $10(5.3)$ & $4(3.8)$ & 0.777 \\
\hline Intraabdominal bleeding & $1(0.5)$ & $0(0)$ & 0.446 & $1(0.5)$ & $0(0)$ & 0.452 \\
\hline Stenosis & $0(0)$ & $0(0)$ & - & $0(0)$ & $0(0)$ & - \\
\hline Motility disorder & $1(0.5)$ & $0(0)$ & 0.446 & $1(0.5)$ & $0(0)$ & 0.452 \\
\hline Anastomosis site leakage & $5(2.5)$ & $1(0.9)$ & 0.420 & $5(2.7)$ & $1(0.9)$ & 0.424 \\
\hline Pulmonary & $5(2.5)$ & $2(1.8)$ & 0.653 & $4(2.1)$ & $2(1.9)$ & 0.888 \\
\hline Other systemic & $1(0.5)$ & $0(0)$ & 0.446 & $1(0.5)$ & $0(0)$ & 0.452 \\
\hline Grade IIIb & $2(1.0)$ & $2(1.8)$ & 0.626 & $2(1.1)$ & $2(1.9)$ & 0.621 \\
\hline Wound & $2(1.0)$ & $1(0.9)$ & 0.904 & $2(1.1)$ & $1(0.9)$ & 0.921 \\
\hline Motility disorder & $0(0)$ & $1(0.9)$ & 0.367 & $0(0)$ & $1(0.9)$ & 0.361 \\
\hline Grade IVa & $2(1.0)$ & $0(0)$ & 0.534 & $2(1.1)$ & $0(0)$ & 0.537 \\
\hline Intraabdominal bleeding & $1(0.5)$ & $0(0)$ & 0.446 & $1(0.5)$ & $0(0)$ & 0.452 \\
\hline Pulmonary & $1(0.5)$ & $0(0)$ & 0.446 & $1(0.5)$ & $0(0)$ & 0.452 \\
\hline Grade IVb & $1(0.5)$ & $0(0)$ & 0.446 & $1(0.5)$ & $0(0)$ & 0.452 \\
\hline Intra-abdominal bleeding & $1(0.5)$ & $0(0)$ & 0.446 & $1(0.5)$ & $0(0)$ & 0.452 \\
\hline \multicolumn{7}{|l|}{$\begin{array}{l}\text { Complication detected from } 1 \\
\text { month to } 1 \text { year }\end{array}$} \\
\hline Delayed EJ stenosis (total no.) & $13(6.6)$ & $6(5.3)$ & 0.807 & $12(6.4)$ & $5(4.7)$ & 0.615 \\
\hline Delayed EJ stenosis ( $\geq$ grade IIla) & $7(3.6)$ & $5(4.4)$ & 0.764 & $6(3.2)$ & $4(3.8)$ & 0.751 \\
\hline Detected period for (Days) & $\begin{array}{l}73.6 \pm \\
19.3\end{array}$ & $\begin{array}{l}74.2 \pm \\
12.7\end{array}$ & 0.942 & $\begin{array}{l}77.4 \pm \\
14.2\end{array}$ & $\begin{array}{l}73.4 \pm \\
14.0\end{array}$ & 0.607 \\
\hline
\end{tabular}

Abbreviations: TLTG = totally laparoscopic total gastrectomy; LATG = laparoscopy-assisted total gastrectomy; $P S M=$ propensity score matching; $E J$ = esophagojejunostomy 
Table 4. Analysis for variables determining the differences of symptom scale between the TLTG and LATG group.

\begin{tabular}{|c|c|c|c|c|}
\hline \multirow{2}{*}{ Symptom scale } & \multirow[t]{2}{*}{ Variable factors } & \multicolumn{2}{|c|}{$\begin{array}{l}\text { Unstandardized } \\
\text { coefficient }\end{array}$} & \multirow[t]{2}{*}{$\begin{array}{l}P \\
\text { value }\end{array}$} \\
\hline & & B & $\begin{array}{l}\text { Standard } \\
\text { errors }\end{array}$ & \\
\hline STO22 dysphagia (6 months) & TLTG (vs LATG) & -20.928 & 5.234 & $<0.001$ \\
\hline \multirow[t]{2}{*}{ STO22 pain (3 months) } & TLTG (vs LATG) & -11.635 & 5.108 & 0.031 \\
\hline & $\begin{array}{l}\text { ST022 pain } \\
\text { (preoperative) }\end{array}$ & 0.419 & 0.202 & 0.047 \\
\hline ST022 pain (6 months) & TLTG (vs LATG) & -16.975 & 5.061 & 0.002 \\
\hline ST022 pain (12 months) & TLTG (vs LATG) & -16.170 & 4.762 & 0.002 \\
\hline \multirow{2}{*}{$\begin{array}{l}\text { STO22 eating restriction ( } 6 \\
\text { months) }\end{array}$} & TLTG (vs LATG) & -11.407 & 4.983 & 0.031 \\
\hline & $\begin{array}{l}\text { ST022 eating } \\
\text { (preoperative) }\end{array}$ & 0.657 & 0.295 & 0.035 \\
\hline \multirow[t]{2}{*}{ OG25 eating (6 months) } & TLTG (vs LATG) & -11.793 & 3.969 & 0.007 \\
\hline & $\begin{array}{l}\text { OG25 eating } \\
\text { (preoperative) }\end{array}$ & 0.663 & 0.230 & 0.008 \\
\hline OG25 eating (12 months) & TLTG (vs LATG) & -13.351 & 5.913 & 0.033 \\
\hline OG25 odynophagia (6 months) & TLTG (vs LATG) & -17.318 & 5.114 & 0.002 \\
\hline
\end{tabular}

Abbreviations: TLTG = totally laparoscopic total gastrectomy; LATG = laparoscopy-assisted total gastrectomy;

\section{Figures}



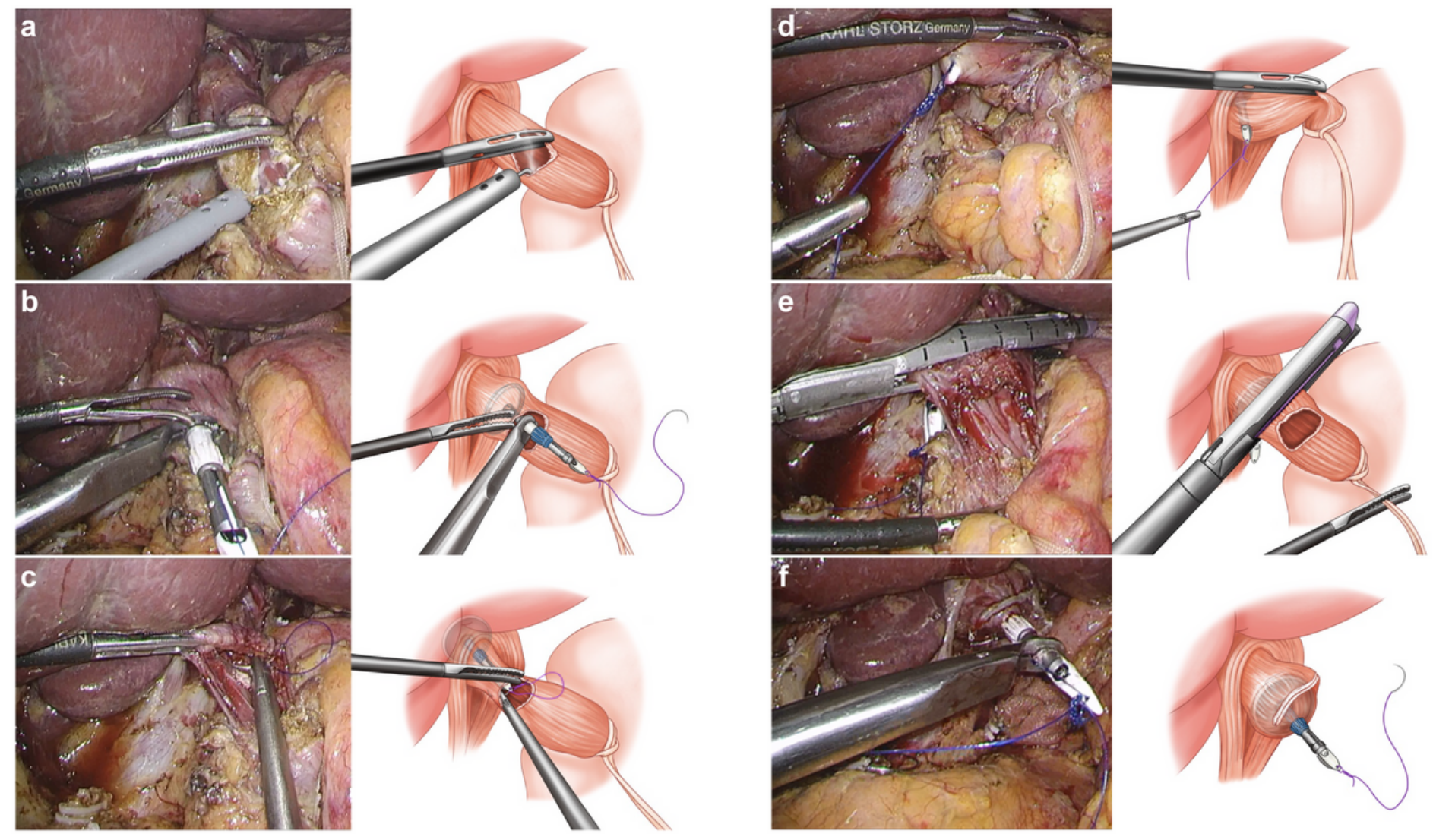

Figure 1

The hemi-double stapling technique for esophagojejunostomy in totally laparoscopic total gastrectomy. a. Opening of the anterior esophageal wall. b. The prepared anvil with stay suture was inserted through the distal esophagotomy site. c. The needle tip was pierced through the medial side of the esophagus. $d$. The anvil rod could be delivered outside by pulling the tied prolene. e. The distal esophagus was transected by linear stapler above the level of the esophagotomy site. f. The anvil shaft was positioned at the tip of stapling line to form hemi-double stapling. 
a

STO22 - Dysphagia

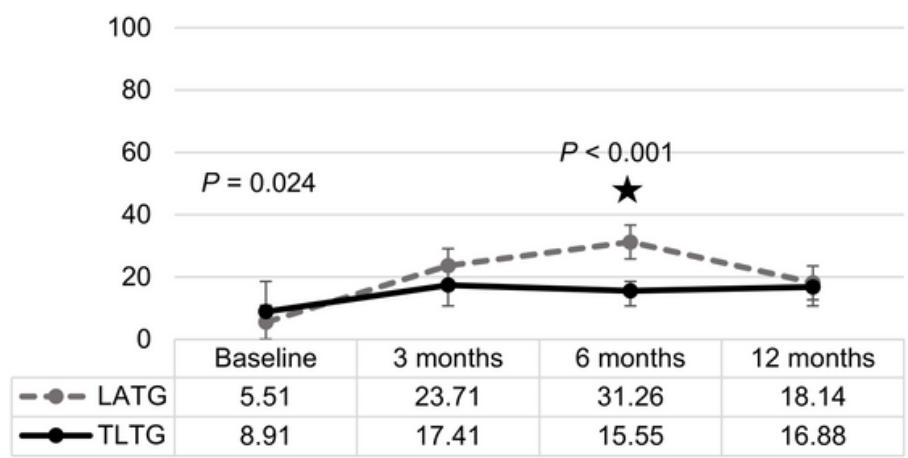

C

STO22 - Eating restrictions

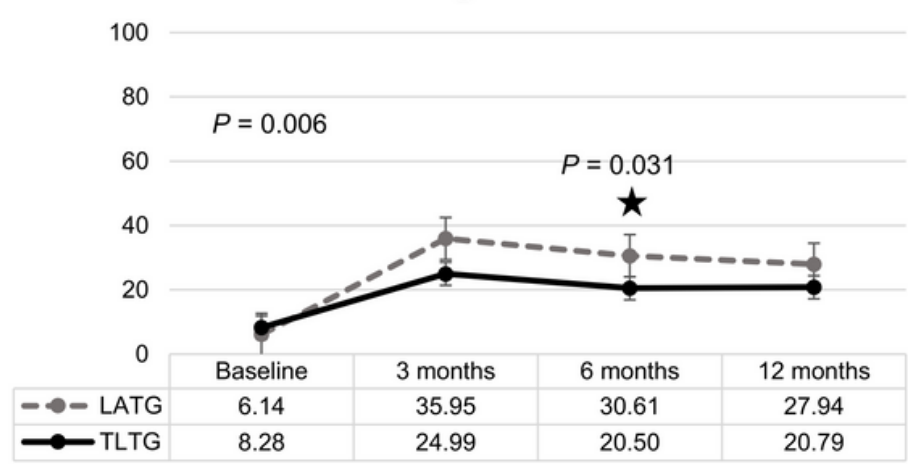

b

STO22 - Pain

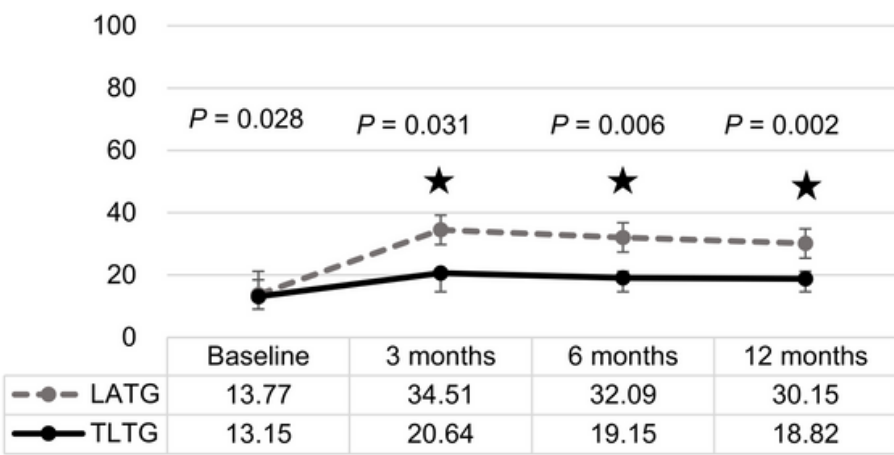

d

OG25 - Eating

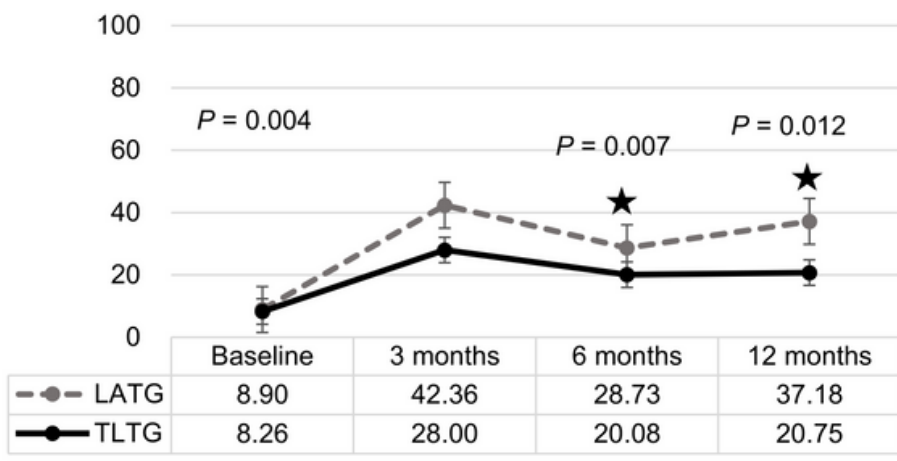

e OG25 - Odynophagia

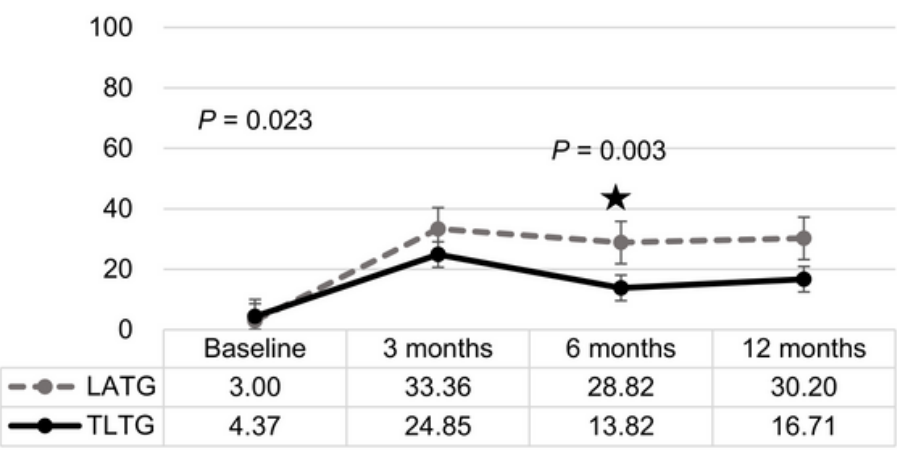

Figure 2

Quality of life between the TLTG group $(n=63)$ and LATG group $(n=21)$ using the EORTC. a. STO22: dysphagia. b. STO22: pain. c. STO 22: eating restriction. d. OG25: eating. e. OG25: odynophagia.

\section{Supplementary Files}

This is a list of supplementary files associated with this preprint. Click to download.

- SuplementarymethodsBMC.pdf

- SuplementarytableBMC.pdf 
- SupplementaryfiguresBMC.pdf

Page 23/23 